Risk factors for surgical site infection after minor dermatological surgery. An analysis of individual participant data from four randomised controlled trials.

Meth Delpachitra, MBBS, Registrar, Royal Brisbane and Women's Hospital, Brisbane, QLD, 4029

Clare Heal, PhD, MBChB, Promotional chair, Discipline of General Practice and Rural Medicine, James Cook University, Mackay, QLD 4740 Australia

Jennifer Banks, PhD, MBS, Senior Research Officer, James Cook University, Mackay, QLD 4740 Australia

Daniel Charles. MBBS, Registrar, Cairns Hospital, Cairns, QLD, 4870

Shampavi Sriharan, MBBS

Petra Buttner, PhD, Adjunct Professor, Epidemiology \& Biostatistics, Centre for Chronic Disease Prevention, James Cook University, Townsville, QLD 4811; Director - Tropical Health Solutions, Townsville, QLD 4811.

Corresponding author: Clare Heal

Sources of funding: Nil

Conflict of interest: none declared 


\begin{abstract}
Background:

Surgical site infection (SSI) after dermatological surgery is associated with poor outcomes including increased recovery time, poor cosmesis and repeat visits to doctors. Prophylactic antibiotics are prescribed to reduce these adverse outcomes. Identifying risk factors for SSI will facilitate judicious antibiotic prophylaxis.
\end{abstract}

Objectives:

To identify risk factors for SSI after minor dermatological surgery.

Design:

Individual patient data from four large randomized controlled trials (RCTs) were combined to increase statistical power.

Setting:

Regional centre in North Queensland, Australia.

Participants:

A total of 3819 adult patients requiring minor skin procedures, were recruited for the four trials over a ten year period.

Main Outcome Measure:

Surgical site infection.

Results:

A total of 298 infections occurred in a population of 3819 patients, resulting in an overall incidence of $7.8 \%$ (95\% CI 5.8-9.6), differing across the four studies $(\mathrm{p}=0.042)$. The risk factors identified were age (Relative Risk (RR) 1.01, 95\% CI 1.001-1.020, $\mathrm{p}=0.008$ ), excisions from the upper limbs (RR 3.03, 95\% CI 1.76-5.22, $\mathrm{p}=0.007$ ), lower limbs (RR 3.99, 95\% CI 1.93-8.23, $\mathrm{p}=0.009$ ) and flap/2-layer procedures (RR 3.23, 95\% CI 1.79-5.85, $\mathrm{p}=0.008)$. Histology of the excised lesion was not a significant independent risk factor for infection. 
Conclusions:

This study demonstrated that patients who were older, underwent complex excisions, or had excisions on the upper or lower limbs, were at higher risk of developing an SSI. An awareness of such risk factors will guide evidence based and targeted antibiotic prophylaxis.

\section{Five Keywords}

Dermatology, surgery, risk, wound, infection

\section{MESH keywords (if required)}

Dermatologic surgery, wound healing, evidence based medicine 


\section{Introduction}

Surgical site infection (SSI) following dermatological surgery is associated with prolonged wound healing, lengthened recovery time, poor cosmetic outcomes and increased costs to the health system. ${ }^{1}$ To avoid negative clinical outcomes for patients, primary care physicians often prescribe prophylactic antibiotics, however a known consequence of liberal antibiotic administration is antibiotic resistance. ${ }^{2}$ Given that antibiotic stewardship guidelines recommend evidence based antibiotic prescription. ${ }^{3}$ awareness of patients who are at higher risk of infection is required to risk-stratify patients and encourage more judicious antibiotic management.

In order to accurately define which patient groups are predisposed to SSI, a comprehensive understanding of patient, procedural and physician related risk factors is necessary. A recent systematic review undertaken by the first author showed that age, sex, histology and type and location of excision were risk factors for SSI following minor skin surgery. ${ }^{4}$ However, several of these studies were limited by small sample sizes and low incidence of infection. ${ }^{5-11}$ Furthermore, only two of these studies (857 patients $8.6 \%$ SSI; 972 patients, $8.7 \% \mathrm{SSI}$ ) were carried out in primary care settings ${ }^{8,9}$. Given that a higher proportion of minor dermatological surgery takes place in primary care than in a hospital or specialist clinic setting in Australia, ${ }^{12}$ this particular area is not well represented in the literature. The review also highlighted the considerably higher incidence of infection in a North Queensland primary care population (8.7\%) compared to the accepted rate of less than $5 \%$ following clean minor surgery. $8,9,13$ The high incidence of SSI makes this population an ideal setting to investigate risk factors for infection.

The aim of this study was to identify the risk factors associated with SSI by conducting a secondary data analysis of the combined individual patient data from four previous randomised controlled trials (RCTs), ${ }^{14-17}$ sourced through convenience sampling. Each trial 
was conducted by two or more authors of this paper, in a regional centre in North Queensland, Australia (Table 1). ${ }^{14-17}$ One trial described a difference between intervention and control groups that was statistically but not clinically significant. ${ }^{15}$ No significant difference was found between the arms of the other three RCTs and consequently all groups were considered together for the purpose of this study. 


\section{Methods}

The data for this study were prospectively collected from four previously published RCTs conducted by one or more authors of the current manuscript. ${ }^{14-17}$. An overview of data collection methods for the four included trials is provided below (additional detail Table 1).

\section{Data collection methods of the included RCTs.}

The four RCTs included in this study were conducted in medical practices in the regional centre of Mackay, North Queensland, Australia. In these four studies, practice nurses were responsible for patient recruitment and demographic/clinical data collection, while general practitioners (GPs) performed the excisions and recorded details related to the excision, including length and type of excision. Across the four studies data was collected on demographics, smoker status, medical conditions (anaemia, diabetes, chronic obstructive pulmonary disease, peripheral vascular disease, ischaemic heart disease and cancer), medications (warfarin, clopidogrel, aspirin, steroids) and lesion and excision details. A body map was used to define excision sites to ensure consistency among participating practices in the four included RCTs. All patients over the age of 18 presenting to their GP for removal of a skin lesion were eligible for recruitment to the RCTs. Only lesions removed by surgical excision were eligible for inclusion, not those involving shave biopsies, electrodesiccation or other methods of surgery. Patients were excluded if they were currently taking oral antibiotics or required immediate postoperative antibiotics or immunosuppressant medication. Repeat patients were excluded and patients were recruited for their first skin excision only during the recruitment period.

A standardised surveillance criterion for superficial SSI developed by the Centers for Disease Control and Prevention (CDC) was employed consistently across the four included RCTs. ${ }^{14-17}$ Surgical site infection was defined as infection of the skin only (or subcutaneous tissue of the excision occurring within 30 days of the excision and including at least one of: purulent 
discharge, pain or tenderness, localised swelling, redness or heat and diagnosis of SSI by a general practitioner. ${ }^{18}$ Stitch abscess was not included as infection.

\section{Data collection protocol for combined individual patient data analysis}

The raw data of the four RCTs were requested from the primary investigators $\mathrm{CH}^{14,15,17}$ and DC ${ }^{16}$ (Table 1). Included RCTs were purposely selected based on convenience sampling. Patient related risk factors such as age, gender, medical history, medication history and smoking status; lesion characteristics such as histology and location; and excision characteristics such as excision length, type, and the time until suture removal comprised the variables under analysis. A 'variable-matrix' was produced to identify which variables were common to the four RCTs. Variables were either numeric or categorical. Numerical variables (e.g. age, length of excision) were directly comparable. Categorical variables varied in their coding such that a second 'recoding-matrix' was produced to visualise the individual coding of all variables, and produce a unique code for each variable/category to be used in the final data set. Not all characteristics from all studies were available for every patient and some variables were missing from entire studies. Of the medical condition variables analysed; cancer was recorded in three trials, ${ }^{14-16}$ ischaemic heart disease was recorded separately in one trial ${ }^{17}$ and reported with other medical conditions in three trials, ${ }^{14-16}$ while anaemia, ${ }^{17}$ hypertension ${ }^{14}$ and inflammatory skin disease ${ }^{16}$ were only recorded in one trial each. Of the medication variables; anticoagulants, inhaled steroids and oral steroids were recorded in three trials, ${ }^{14-16}$ and immuno-suppressants, ${ }^{17}$ opioids ${ }^{17}$ and disease-modifying-anti-rheumatic-drugs ${ }^{16}$ were only recorded in one trial. Smoking status and excision length were recorded in three trials. ${ }^{14-}$ 16

\section{Statistical methods for combined individual patient data analysis}

Statistical analysis was performed using STATA-IC (version 14.0; StataCorp, TX, USA). Analyses were adjusted for the two-stage cluster sampling design (trial and recruiting 
GP) using the svy commands in STATA. A p-value of less than 0.05 was considered statistically significant.

For descriptive analysis of categorical data, absolute and relative frequencies were calculated. Incidence of SSI was presented with 95\% confidence intervals (95\% CI). Numerical data were first assessed for normality. All numerical variables in the data set (age, length of excision, time to suture removal) were skewed and were therefore described using median, interquartile range (IQR), and range. For inferential analysis comparing patients with SSI and those with no SSI, Chi-square and Fisher's exact tests were applied for categorical variables, and Wilcoxon rank-sum tests were used for numerical data.

Cluster-adjusted generalised linear modelling using Poisson regression was used to estimate relative risks and 95\% CI. Categorical characteristics were analysed using indicator variables. Stepwise forward and backward selection processes were conducted to reach a model. All remaining characteristics that were not in this model were investigated for their potential confounding effects. A variable was considered a confounder if it altered the estimate by more than $10 \%$. The final model was adjusted for all identified confounders. All possible two-way interactions of characteristics in the model were investigated.

\section{Study Approval}

Approval for this analysis was covered by the individual ethics approvals of the four included trials. Approval was provided by James Cook University Human Research Ethics Committee (H1902, H2590, H4572 and H6065).

\section{Results}

Data from 3819 patients were available for analysis and an overview of the four trials, including total sample size and incidence of SSI is presented in Table 1. Patient characteristics are presented in Table 2 and clinical details regarding the excisions are presented in Table 3. 
The median age of the 3819 patients was 63 years, with a similar distribution of males to females $(54.9 \%$ vs. $45.1 \%)$.

[Table 1 here]

[Table 2 here]

[Table 3 here]

\section{Risk factors for surgical site infection}

SSI occurred in 298 (7.8\%; 95\% CI 5.8-9.6) of the 3819 skin excisions and the infection rates for the four trials were $7.3 \%, 9.0 \%, 9.0 \%$ and $6.3 \%(\mathrm{p}=0.042)$ (Table 1). Patients who developed a SSI were, on average, 6 years older than patients without a SSI ( $\mathrm{p}=0.004)$. Of all the medical diagnoses recorded, only the presence of cancer was significantly associated with a higher incidence of SSI ( $\mathrm{p}=0.029)$ (Table 2). Although patients who took any medication mentioned in the four trials had a higher incidence of infection $(\mathrm{p}=0.045)$, individually no medication was significantly associated with infection (Table 2). Patients who were current or ex-smokers had a higher incidence of infection compared to non-smokers, however this relationship was not statistically significant $(\mathrm{p}=0.261)$.

Skin excisions that took place on the upper limbs $(10.6 \%)$ or lower limbs $(10.8 \%)$ had a higher incidence of infection compared to other body sites $(\mathrm{p}=0.044)$ (Table 3). Excisions of squamous cell (12.8\%), melanocytic (8.5\%) and basal cell (8.4\%) carcinomas were more likely to become infected compared to lesions with other histological classifications $(p=0.006)$ (Table $3)$.

There was a statistically significant difference in the median duration to removal of sutures between the infected and non-infected lesions, although this difference was only one day $(\mathrm{p}=0.023)$. More complex procedures such as flap or 2-layer procedures were also more likely to develop SSI compared to simple elliptical excisions ( $\mathrm{p}=0.002)$ (Table 3). 
Multivariable generalised linear modelling (Table 4) confirmed that there was a 1.01 times risk of infection per one-year increase in age $(\mathrm{p}=0.008)$. Excisions from the lower limbs were 3.99 times more likely, excisions from the upper limbs 3.03 times more likely and excisions from the trunk 2.07 times more likely to become infected compared to excisions on the head or neck ( $\mathrm{p}=0.009,0.007$ and 0.031 respectively). The type of excision (flap/2-layer vs. simple excisions) was also an independent predictor of SSI ( $\mathrm{p}=0.008)$.

[Table 4] 


\section{Discussion}

Our results suggest that increasing age, excisions from the trunk, upper or lower limbs and flap/2-layer procedures are significant independent risk factors for SSI. Similar results have been demonstrated in previous literature. ${ }^{6-9}$

Few studies have identified age as a risk factor for SSI, and it was not an identified risk factor in any of the individual trial analyses. Although the risk per one-year increase is small, this indicates a relationship between increasing age and SSI risk, particularly when the age difference is larger. Only one other study reported similar findings, describing an increased risk of SSI with age over 50 years. $^{7}$ While there is no explicit evidence that explains the relationship between age and SSI, aging is known to negatively impact wound healing through many physiological processes. ${ }^{19}$ This relationship might explain the increased risk of SSI. Further exploration of this risk factor (i.e. identifying an appropriate age threshold) is required before translating this finding to practice.

Upper and lower limb excisions were risk factors for SSI in this study, which is consistent with several studies conducted in both hospital and primary care settings. ${ }^{5,8,9,11,20}$ Body extremities have reduced perfusion and compromised circulation compared to more central areas, implying a poorer wound healing process, which may explain why this phenomenon was observed. Excisions on the trunk were also significantly associated with SSI. However the observed incidence of SSI was only $1.8 \%$ higher compared to the reference category of head and neck excisions (Table 3), and such a minor difference might be considered clinically irrelevant. The statistical significance was due to the large sample size of the study and its respective power to detect even negligible differences.

Patients who received flap or 2-layer procedures for more complicated wounds were approximately three times more likely to develop an SSI compared to patients who received simple elliptical excisions. This relationship has been explored in three other studies. ${ }^{10,11,21}$. 
More complex procedures such as these, although designed to reduce wound tension, have a higher overall tension compared to small wound closures. It is possible that higher wound tension makes the site more susceptible to wound breakage and opening, and therefore to subsequent infection.

The histology of excised lesions has been discussed as a predictor of SSI in earlier literature. $^{8,9}$ In this dataset, excisions of melanocytic (melanoma) and non-melanocytic (squamous and basal cell carcinoma) skin cancers were significantly associated with a higher incidence of infection on bivariate analysis, however this relationship was not shown to be independently significant in the multivariate model. As malignant skin lesions are more likely to occur on the extremities due to cumulative sun exposure, ${ }^{22-24}$ there was a high degree of correlation between histology and body site. Indeed, histology of the lesion was identified as a confounder of body site in the multivariable analysis and the model was adjusted for its effects.

There were several advantages to our approach of combining individual patient data from a convenience sample of four randomised controlled trials previously conducted by the researchers. The original raw data from these trials were immediately available to the researchers. This data was collected prospectively from similar patient groups, and therefore the clinically homogenous nature of this data allowed for meaningful synthesis. Combination of this data allowed analysis of a very large patient population, providing increased statistical power to identify risk factors for infection.

\section{Limitations}

The limitations of this study design is that the sample was limited to studies conducted in one centre, and generalizability may be impacted by two factors; 1) all trials involved were carried out in a regional, hot and humid tropical setting and 2) the occupations of the patients included in the study would differ from those residing in a metropolitan area, introducing 
factors such as risk of injury and exposure to different microbial species. It is possible that the warm and humid climate of North Queensland is associated with a higher incidence of infection. As such, the findings of this study might not be directly applicable to other areas which may or may not impact the infection rate and the risk factors involved.

Some variables (or categories of variables) were not collected in certain trials and these variables were omitted from the final multivariable model, reducing the overall power of the analysis. A further limitation is that the data from the included studies was not collected specifically for the purposes of a combined individual patient data analysis. Imputation of data is routinely performed to rectify this issue, however the missing values were often for entire trials, making imputation unfeasible. Although information pertaining to past medical history was collected by practice nurses, medical diagnoses were extracted from the practice's medical management software, rather than standardised diagnostic criteria. This may explain the lack of any significant associations between past medical history and incidence of infection.

\section{Conclusion.}

Antibiotic prophylaxis is prescribed unnecessarily for patients undergoing minor dermatological surgery, and should be restricted to patients who are at higher risk of developing a SSI. This combined data-analysis identified that older age, excisions from the upper and lower limbs and flap or 2-layer procedures were significant risk factors for SSI in a large general practice cohort. We hope that the identification of these risk factors will help to encourage judicious antibiotic prophylaxis for patients undergoing minor skin surgery in general practice. 


\section{References}

1. Bratzler DW, Houck PM, Surgical Infection Prevention Guideline Writers W. Antimicrobial prophylaxis for surgery: an advisory statement from the National Surgical Infection Prevention Project. Am J Surg. 2005;189(4):395-404.

2. Ventola CL. The antibiotic resistance crisis: part 1: causes and threats. $\mathrm{P} T$. 2015;40(4):277-83.

3. Antibiotic Expert Group e. Therapeutic guidelines: antibiotic. Melbourne: Therapeutic Guidelines Ltd.; 2006.

4. Delpachitra MR, Heal C, Banks J, Divakaran P, Pawar M. Risk Factors for Surgical Site Infection in Minor Dermatological Surgery: A Systematic Review. Adv Skin Wound Care. 2018.

5. Bordeaux JS, Martires KJ, Goldberg D, Pattee SF, Fu P, Maloney ME. Prospective evaluation of dermatologic surgery complications including patients on multiple antiplatelet and anticoagulant medications. Journal of the American Academy of Dermatology. 2011;65(3):576-83.

6. Dixon AJ, Dixon MP, Askew DA, Wilkinson D. Prospective study of wound infections in dermatologic surgery in the absence of prophylactic antibiotics. Dermatologic surgery : official publication for American Society for Dermatologic Surgery [et al]. 2006;32(6):819-7. 7. Gabrielli F, Potenza C, Puddu P, Sera F, Masini C, Abeni D. Suture materials and other factors associated with tissue reactivity, infection, and wound dehiscence among plastic surgery outpatients. Plastic and Reconstructive Surgery. 2001;107(1):38-45.

8. Heal C, Buettner P, Browning S. Risk factors for wound infection after minor surgery in general practice. Medical Journal of Australia. 2006;185(5):255-8.

9. Heal CF, Buettner PG, Drobetz H. Risk factors for surgical site infection after dermatological surgery. International Journal of Dermatology. 2012;51(7):796-803.

10. Sylaidis P, Wood S, Murray DS. Postoperative infection following clean facial surgery. Annals of plastic surgery. 1997;39(4):342-6.

11. Penington A. Ulceration and antihypertensive use are risk factors for infection after skin lesion excision. ANZ journal of surgery. 2010;80(9):642-5.

12. Pollack A, McGrath M, Henderson J, Britt H. Skin cancer by state and territory. Aust Fam Physician. 2014;43(8):507.

13. Kothapalli A. Postoperative wound infection rates following diagnostic skin biopsies in dermatology patients at an Australian tertiary hospital. Australas J Dermatol. 2019;60(1):778 .

14. Heal C, Sriharan S, Buttner PG, Kimber D. Comparing non-sterile to sterile gloves for minor surgery: a prospective randomised controlled non-inferiority trial. The Medical journal of Australia. 2015;202(1):27-31.

15. Heal CF, Buettner PG, Cruickshank R, Graham D, Browning S, Pendergast J, et al. Does single application of topical chloramphenicol to high risk sutured wounds reduce incidence of wound infection after minor surgery? Prospective randomised placebo controlled double blind trial. BMJ (Clinical research ed). 2009;338:a2812.

16. Charles D, Heal CF, Delpachitra M, Wohlfahrt M, Kimber D, Sullivan J, et al. Alcoholic versus aqueous chlorhexidine for skin antisepsis: the AVALANCHE trial. CMAJ. 2017;189(31):E1008-E16.

17. Heal C, Buettner P, Raasch B, Browning S, Graham D, Bidgood R, et al. Can sutures get wet? Prospective randomised controlled trial of wound management in general practice. BMJ. 2006;332(7549):1053-6. 
18. Mangram AJ, Horan TC, Pearson ML, Silver LC, Jarvis WR. Guideline for prevention of surgical site infection, 1999. Hospital Infection Control Practices Advisory Committee. Infect Control Hosp Epidemiol. 1999;20(4):250-78; quiz 79-80.

19. Sgonc R, Gruber J. Age-related aspects of cutaneous wound healing: a mini-review. Gerontology. 2013;59(2):159-64.

20. Wahie S, Lawrence CM. Wound complications following diagnostic skin biopsies in dermatology inpatients. Archives of Dermatology. 2007;143(10):1267-71.

21. Schliephake H, Neukam FW, Schmelzeisen R, Reiche C. Reconstruction of facial soft tissues after resection of skin tumors. Journal of cranio-maxillo-facial surgery : official publication of the European Association for Cranio-Maxillo-Facial Surgery. 1994;22(6):3428.

22. Ilyas EN, Leinberry CF, Ilyas AM. Skin cancers of the hand and upper extremity. J Hand Surg Am. 2012;37(1):171-8.

23. Armstrong BK. How sun exposure causes skin cancer: an epidemiological perspective. In: Hill D, Elwood JM, English DR, editors. Prevention of Skin Cancer. Dordrecht: Springer Netherlands; 2004. p. 89-116.

24. Heal C, Buettner P, Raasch B, Browning S. Minor skin excisions in general practice in North Queensland. Aust Fam Physician. 2006;35(10):825-8. 
Tables

Table 1.

\begin{tabular}{|c|c|c|c|c|}
\hline $\begin{array}{c}\text { First author } \\
\text { year }\end{array}$ & Study details/Methods & $\begin{array}{l}\text { Sample } \\
\text { Size (\% } \\
\text { of total) }\end{array}$ & SSI* & $\begin{array}{l}\text { Incidence } \\
\text { of SSI \% }\end{array}$ \\
\hline $\begin{array}{c}\text { Heal et al. }{ }^{17} \\
2006\end{array}$ & $\begin{array}{l}\text { Multicentre randomised controlled trial. Consecutive } \\
\text { patients presenting for minor skin excision. Dry } \\
\text { covered wounds (control) vs wounds uncovered and } \\
\text { wet within } 48 \mathrm{hrs} \text { of excision (intervention). } \\
\text { Exclusions: patients on/clinically indicated for } \\
\text { antibiotics, lacerations, flap or two layer procedures, } \\
\text { excision of sebaceous cyst and skin excision on facial } \\
\text { site. }\end{array}$ & $\begin{array}{c}1247 \\
(32.7 \%)\end{array}$ & 91 & 7.3 \\
\hline $\begin{array}{c}\text { Heal et al. } .^{15} \\
2009\end{array}$ & $\begin{array}{l}\text { Multicentre double blind randomised controlled trial. } \\
\text { Consecutive patients presenting for minor skin } \\
\text { excision. Single dose topical chloramphenicol } \\
\text { (intervention) vs paraffin ointment (control). } \\
\text { Exclusions: patients on/clinically indicated for } \\
\text { antibiotics, patients on immune-suppressants, excision } \\
\text { of sebaceous cyst, allergy to chloramphenicol and } \\
\text { personal or family history of aplastic anaemia. }\end{array}$ & $\begin{array}{c}1185 \\
(31.0 \%)\end{array}$ & 107 & 9.0 \\
\hline $\begin{array}{c}\text { Heal et al. }{ }^{14} \\
2015\end{array}$ & $\begin{array}{l}\text { Single centre randomised controlled trial. Consecutive } \\
\text { patients presenting for minor skin excision. Clean } \\
\text { boxed non-sterile gloves (intervention) vs sterile gloves } \\
\text { (control). Exclusions: patients on antibiotics or } \\
\text { immune-suppressants, skin flaps, excision of sebaceous } \\
\text { cyst and allergy to latex. }\end{array}$ & $\begin{array}{c}478 \\
(12.5 \%)\end{array}$ & 43 & 9.0 \\
\hline $\begin{array}{c}\text { Charles et al. }^{16} \\
2016\end{array}$ & $\begin{array}{l}\text { Multi centre randomised controlled trial. Consecutive } \\
\text { patients presenting for minor skin excision. Topical } \\
\text { application of } 0.5 \% \text { chlorhexidine in } 70 \% \text { ethanol } \\
\text { (intervention) vs } 0.5 \% \text { chlorhexidine in aqueous } \\
\text { solution. Exclusions: patients on antibiotics, excision } \\
\text { of sebaceous cyst and allergy to alcohol or } \\
\text { chlorhexidine. }\end{array}$ & $\begin{array}{c}909 \\
(23.8 \%)\end{array}$ & 57 & 6.3 \\
\hline Total & Total & 3819 & 298 & 7.8 \\
\hline
\end{tabular}

Table 1 Legend. RCTs included in the IPD meta-analysis. The studies included one equivalence study, ${ }^{17}$ one non-inferiority study, ${ }^{14}$ and two studies testing for difference. ${ }^{15}$, 16 Sample sizes in each trial are indicated alongside numbers of SSI (surgical site infection). The rate of SSI is also presented. 
Table 2.

\begin{tabular}{|c|c|c|c|c|}
\hline Patient characteristics $^{\mathrm{b}}$ & $\begin{array}{c}\text { Overall } \\
(n=3819)\end{array}$ & SSI $(n=298)$ & $\begin{array}{l}\text { Incidence } \\
\text { of SSI }\end{array}$ & p-value ${ }^{a}$ \\
\hline $\operatorname{Age}^{\mathrm{c}}(\mathrm{IQR})^{\mathrm{d}}$, range $(\mathrm{n}=3794)$ & $\begin{array}{l}63(50,73) ; \\
\text { range } 5 \text { to } 101\end{array}$ & $\begin{array}{l}68(58,75) ; \\
\text { range } 15 \text { to } 91 \\
\end{array}$ & - & $\begin{array}{l}\mathrm{P}<0.001 \\
\mathrm{P}=0.004\end{array}$ \\
\hline Male $(\%)$ & $2095(54.9 \%)$ & $183(61.4 \%)$ & & $\begin{array}{l}\mathrm{P}=0.018 \\
\mathrm{P}=0.056\end{array}$ \\
\hline \multicolumn{5}{|l|}{ Medical conditions (\%) } \\
\hline Any condition ${ }^{\mathrm{e}}$ & $520(13.6 \%)$ & $58(19.5 \%)$ & $10.6 \%$ & $\begin{array}{l}\mathrm{P}=0.002 \\
\mathrm{P}=0.113\end{array}$ \\
\hline Anaemia $^{4}(\mathrm{n}=478)$ & $1(0 \%)$ & $0(0 \%)$ & $0.0 \%$ & $\mathrm{P}=1.0$ \\
\hline Cancer $^{1,3,4}(\mathrm{n}=2572)$ & $50(1.9 \%)$ & $11(5.3 \%)$ & $22.0 \%$ & $\begin{array}{l}\mathrm{P}<0.001 \\
\mathrm{P}=0.029\end{array}$ \\
\hline COPD & $62(1.6 \%)$ & $9(3.0 \%)$ & $14.5 \%$ & $\begin{array}{l}\mathrm{P}=0.047 \\
\mathrm{P}=0.496\end{array}$ \\
\hline Diabetes $(\mathrm{n}=3818)$ & $285(7.5 \%)$ & $33(11.1 \%)$ & $11.6 \%$ & $\begin{array}{l}\mathrm{P}=0.014 \\
\mathrm{P}=0.109\end{array}$ \\
\hline Hypertension $^{4}(\mathrm{n}=478)$ & $119(24.9 \%)$ & $6(14.0 \%)$ & $5.0 \%$ & $\begin{array}{l}\mathrm{P}=0.082 \\
\mathrm{P}=0.098\end{array}$ \\
\hline $\begin{array}{l}\text { Ischaemic Heart Disease }{ }^{3,4} \\
(\mathrm{n}=1663)\end{array}$ & $45(2.7 \%)$ & $6(4.0 \%)$ & $13.0 \%$ & $\begin{array}{l}\mathrm{P}=0.306 \\
\mathrm{P}=0.839\end{array}$ \\
\hline $\begin{array}{l}\text { Inflammatory Skin Disease }{ }^{1} \\
(\mathrm{n}=909)\end{array}$ & $2(0.2 \%)$ & $0(0 \%)$ & $0.0 \%$ & $\mathrm{P}=1.0$ \\
\hline Peripheral Vascular Disease & $19(0.5 \%)$ & $1(0.3 \%)$ & $5.3 \%$ & $\begin{array}{c}\mathrm{P}=1.0 \\
\mathrm{P}=0.586\end{array}$ \\
\hline \multicolumn{5}{|l|}{ Medications (\%) } \\
\hline Any medication ${ }^{\mathrm{e}}$ & $602(15.8 \%)$ & $64(21.5 \%)$ & $10.6 \%$ & $\begin{array}{l}\mathrm{P}=0.005 \\
\mathrm{P}=0.045\end{array}$ \\
\hline Anticoagulants ${ }^{14-16}$ ( $\mathrm{n}=2572$ ) & $204(7.9 \%)$ & $19(9.2 \%)$ & $9.3 \%$ & $\begin{array}{l}\mathrm{P}=0.489 \\
\mathrm{P}=0.424\end{array}$ \\
\hline Antiplatelet ${ }^{14-16}$ & $329(8.6 \%)$ & $37(12.4 \%)$ & $11.3 \%$ & $\begin{array}{l}\mathrm{P}=0.015 \\
\mathrm{P}=0.081\end{array}$ \\
\hline Daily inhaled steroids ${ }^{14-16}(\mathrm{n}=2570)$ & $66(2.6 \%)$ & $6(2.9 \%)$ & $9.1 \%$ & $\begin{array}{l}\mathrm{P}=0.754 \\
\mathrm{P}=0.940\end{array}$ \\
\hline Immuno-suppressants ${ }^{16}(\mathrm{n}=909)$ & $12(1.3 \%)$ & $2(3.5 \%)$ & $16.0 \%$ & $\begin{array}{l}\mathrm{P}=0.135 \\
\mathrm{P}=0.344\end{array}$ \\
\hline Opioids $^{16}(\mathrm{n}=909)$ & $8(0.9 \%)$ & $0(0 \%)$ & $0.0 \%$ & $\begin{array}{c}\mathrm{P}=1.0 \\
/\end{array}$ \\
\hline
\end{tabular}




\begin{tabular}{|c|c|c|c|c|}
\hline $\begin{array}{l}\text { Medications cont. (\%) } \\
\text { Oral steroids }{ }^{14-16}(\mathrm{n}=2572)\end{array}$ & $45(1.7 \%)$ & $6(2.9 \%)$ & $13.3 \%$ & $\mathrm{P}=0.189$ \\
$\begin{array}{c}\text { Disease-Modifying Anti-rheumatic } \\
\text { drugs }^{16}(\mathrm{n}=478)\end{array}$ & $2(0.4 \%)$ & $0(0 \%)$ & $0.0 \%$ & $\mathrm{P}=0.593$ \\
\hline Smoking status (\%) $)^{14-16}(\mathrm{n}=2752)$ & $1579(61.9 \%)$ & $115(56.7 \%)$ & $7.3 \%$ & $\mathrm{P}=0.250$ \\
Non-smoker & $678(26.6 \%)$ & $63(31.0 \%)$ & $9.3 \%$ & $\mathrm{P}=0.261$ \\
Ex-smoker & $292(11.5 \%)$ & $25(12.3 \%)$ & $8.6 \%$ & \\
\hline
\end{tabular}

Table 2 Legend. Description of patient characteristics of 3819 patients undergoing minor skin excision and comparisons between patients with and patients without surgical site infection (SSI). The data combines results from 4 clinical trials. ${ }^{a}$ p-values: first $\mathrm{p}$-value is result of unadjusted analysis and second

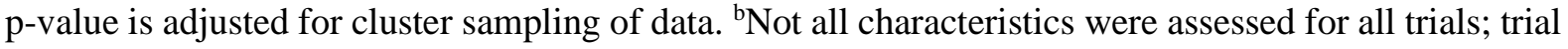
number and/or sample sizes stated for variables with less than 3819 valid entries; ' $a g e$ (years) presented as median; ${ }^{\mathrm{d}} \mathrm{IQR}=$ inter-quartile range; 'Denominator for "any" condition or medication mentioned in pooled data combines "no" and "missing values" for trials which did not record certain conditions or medications. Superscript numbers adjacent to variables denote which trial the variable was recorded in. No number indicates the variable was recorded in all four trials. 
Table 3.

\begin{tabular}{|c|c|c|c|c|}
\hline Excision characteristic ${ }^{b}$ & $\begin{array}{c}\text { Overall } \\
(n=3819)\end{array}$ & SSI $(n=298)$ & SSI rate & p-value ${ }^{a}$ \\
\hline Histology $(\%)(n=3818)$ & & & & $\begin{array}{l}\mathrm{P}<0.001 \\
\mathrm{P}=0.006\end{array}$ \\
\hline Basal Cell Carcinoma & $854(22.4 \%)$ & $72(24.2 \%)$ & $8.4 \%$ & \\
\hline Squamous Cell Carcinoma/ & $935(24.5 \%)$ & $120(40.3 \%)$ & $12.8 \%$ & \\
\hline Bowen's disease & & & & \\
\hline Melanoma & $59(1.5 \%)$ & $5(1.7 \%)$ & $8.5 \%$ & \\
\hline Benign naevus & $333(8.7 \%)$ & $10(3.4 \%)$ & $3.0 \%$ & \\
\hline Dysplastic naevus & $90(2.4 \%)$ & $2(0.7 \%)$ & $2.2 \%$ & \\
\hline Actinic keratosis & $775(20.3 \%)$ & $62(20.8 \%)$ & $8.0 \%$ & \\
\hline Seborrheic keratosis & $220(5.8 \%)$ & $9(3.0 \%)$ & $4.1 \%$ & \\
\hline Other histology $y^{c}$ & $552(14.5 \%)$ & $18(6.0 \%)$ & $3.3 \%$ & \\
\hline Location (\%) $(\mathrm{n}=3794)$ & & & & $\begin{array}{l}\mathrm{P}<0.001 \\
\mathrm{P}=0.044\end{array}$ \\
\hline Head and neck & $869(22.9 \%)$ & $26(8.8 \%)$ & $3.0 \%$ & \\
\hline Upper limbs & $1269(33.4 \%)$ & $134(45.6 \%)$ & $10.6 \%$ & \\
\hline Trunk & $736(19.4 \%)$ & $35(11.9 \%)$ & $4.8 \%$ & \\
\hline Lower limbs & $920(24.2 \%)$ & $99(33.7 \%)$ & $10.8 \%$ & \\
\hline $\begin{array}{l}\text { Excision length }^{\mathrm{d} 1,3,4}(\mathrm{IQR}) ; \text { range } \\
(\mathrm{n}=2572)\end{array}$ & $\begin{array}{l}20(15,30) ; \\
\text { range } 1.5 \text { to } 100\end{array}$ & $\begin{array}{l}27(20,38) \\
\text { range } 6 \text { to } 80\end{array}$ & - & $\begin{array}{l}\mathrm{P}<0.001 \\
\mathrm{P}=0.050\end{array}$ \\
\hline $\begin{array}{l}\text { Flap/2-layer procedure }(\%) \\
(n=3815)\end{array}$ & $54(1.4 \%)$ & $15(5.1 \%)$ & $27.8 \%$ & $\begin{array}{l}\mathrm{P}<0.001 \\
\mathrm{P}=0.002\end{array}$ \\
\hline $\begin{array}{l}\text { Days to suture removale }(\mathrm{IQR}) ; \\
\text { range }(\mathrm{n}=3710)\end{array}$ & $\begin{array}{l}8(7,10) \\
\text { range } 1 \text { to } 37\end{array}$ & $\begin{array}{c}9(7,11) \text {; range } 3 \text { to } \\
18\end{array}$ & - & $\begin{array}{l}\mathrm{P}<0.001 \\
\mathrm{P}=0.023\end{array}$ \\
\hline
\end{tabular}

Table 3. Description of excision characteristics of 3819 patients undergoing minor skin excision and comparisons between patients with and patients without surgical site infection (SSI). The data combines results from 4 clinical trials. ${ }^{a} \mathrm{p}$-values: first $\mathrm{p}$-value is result of unadjusted analysis and second $\mathrm{p}$-value is adjusted for cluster sampling of data. ${ }^{b}$ Not all characteristics were assessed for all trials; trial number and/or sample sizes stated for variables with less than 3819 valid entries; ${ }^{\circ}$ Other histology included basal cell papilloma, re-excisions of melanoma, dysplastic naevus, and non-melanoma skin cancers; ${ }^{\mathrm{d}}$ excision length $(\mathrm{mm})$ presented as median; ${ }^{\mathrm{e}}$ number of days until sutures were removed, presented as median; / = no result calculated as there were too few events observed. Superscript numbers adjacent to variables denote which trial the variable was recorded in. No number indicates the variable was recorded in all four trials. 
Table 4.

\begin{tabular}{|c|c|c|c|c|c|}
\hline Characteristic & $\begin{array}{l}\text { With no SSI } \\
(n=3495)\end{array}$ & $\begin{array}{l}\text { With SSI } \\
(\mathrm{n}=292)\end{array}$ & $\begin{array}{l}\text { Relative } \\
\text { Risk }\end{array}$ & $\begin{array}{l}95 \% \text { Confidence } \\
\text { interval }\end{array}$ & p-value \\
\hline Age [years] & /* & I & 1.01 & 1.001 to 1.02 & $\mathrm{P}=0.008$ \\
\hline \multicolumn{6}{|l|}{ Body site of lesion } \\
\hline Head and Neck & $840(24.0 \%)$ & $26(8.9 \%)$ & 1 & & \\
\hline Upper limbs & $1135(32.5 \%)$ & $132(45.2 \%)$ & 3.03 & 1.76 to 5.22 & $\mathrm{P}=0.007$ \\
\hline Trunk & $699(20.0 \%)$ & $35(12.0 \%)$ & 2.07 & 1.13 to3.79 & $\mathrm{P}=0.031$ \\
\hline Lower limbs & $821(23.5 \%)$ & $99(33.9 \%)$ & 3.99 & 1.93 to 8.23 & $\mathrm{P}=0.009$ \\
\hline \multicolumn{6}{|l|}{ Type of excision } \\
\hline Simple excision & $3456(98.9 \%)$ & $277(94.9 \%)$ & 1 & & \\
\hline Flap or 2 layer excision & $39(1.1 \%)$ & $15(5.1 \%)$ & 3.23 & 1.79 to 5.85 & $\mathrm{P}=0.008$ \\
\hline
\end{tabular}

Table 4 Legend. Result of generalised linear modelling of risk factors for SSI in 3787 patients with minor skin surgery. *Age is a continuous characteristic. Model was adjusted for the confounding effects of histology of lesion. 
